\title{
Health Literacy as a Global Public Health Concern: A Systematic Review
}

\author{
Madeeha Malik*1, Rubab Zehra Zaidii ${ }^{2}$ and Azhar Hussain ${ }^{3}$ \\ ${ }^{1}$ Director/Associate Professor, Hamdard Institute of Pharmaceutical Sciences, Hamdard University, Pakistan \\ ${ }^{2}$ M.Phil Scholar, Hamdard Institute of Pharmaceutical Sciences, Hamdard University, Islamabad Pakistan \\ ${ }^{3}$ Dean/Professor, Hamdard Institute of Pharmaceutical Sciences, Hamdard University, Islamabad Pakistan
}

Submission: November 05, 2017; Published: November 13, 2017

*Corresponding author: Madeeha Malik, Hamdard Institute of Pharmaceutical Sciences, Hamdard University, Islamabad, Pakistan, Email: madeehamalik15@gmail.com

\begin{abstract}
Low health literacy is known to be a 'silent killer'. This can be tackled by closing the gaps between health messages and health messengers by using simplified language and including cultural appropriateness. The aim of this review paper was to systematically analyze the concept of health literacy, its measurement tools and related barriers along with interventions used to improve health literacy in developed and developing countries including Pakistan. A total of 54 studies were retrieved from databases related to health literacy among which 33 studies were from developed countries, 16 from developing countries, and 5 studies from Pakistan. The review paper concludes that the multiple dimensions of health literacy are still yet to be clearly explained. Most of the studies used either REALM or TOFHLA for measurement of health literacy, which are not sufficient for measuring health literacy beyond the ability to read and understand medical information.

Although, health literacy in most of the developed countries is adequate but it is still questionable in developing countries including Pakistan. Limited studies have examined impact of different interventions for improving health literacy especially in specific populations. Extensive research is required to explore economic implications of limited health literacy on the health system and the cost-effectiveness of interventions to improve health literacy. Furthermore, effectiveness of media literacy education addressing health and language barrier to comprehend medical instructions, prescriptions and drug labels should be investigated.
\end{abstract}

Keywords: Barriers; Developed countries; Developing countries; Health literacy; Interventions; Pakistan

\section{Introduction}

The term, health literacy, was primarily created in 1974 [1]. A person is said to be health literate if he/she is able to understand complex vocabulary, can easily share personal information with health care providers, is able to take decisions for spending a healthy lifestyle, can actively participate in self care and chronic disease management and is capable enough to navigate a complex health care system [2]. The Ottawa Charter of Health Promotion states that health is a resource for life, not the object of living hence it is important to possess adequate health literacy skills in order to apply health concepts in different stages of life and actively take part in health related discussions. Attaining health literacy is a lifelong process and is affected by different factors such as demographic, physical health status, socio-political, psychosocial and cultural factors [3].

There is a conflict of opinion among researchers in defining whether health literacy is a static or dynamic concept. Generally it is defined as static i.e. the health literacy level of an individual remains same throughout life and very intense educational classes are required to improve its level. Thus it needs to be measured once in a lifetime to designate a specific health literacy level to a person. On the other side some specialists like Zarcadoolas and his fellow researchers consider it to be dynamic i.e. health literacy level changes with the experience gained in tackling different health circumstances and making health related choices in life, thus in this case health literacy level needs to be measured and re-evaluated repeatedly. The modern world is taking into consideration its dynamic concept more than its static one. Considering health literacy fixed or dynamic has marked implications not only on its definition but also on its measurement techniques [4].

Low health literacy is known to be a 'silent killer'. This can be tackled by closing the gaps between health messages and health messengers by using simplified language and including cultural appropriateness [5]. Literature review confirms that both written and verbal health information combined are necessary to improve the knowledge and level of satisfaction of care givers at the time of discharging their patients as compared 
to provision of verbal information only [5,6]. Patients with poor health literacy experience communication difficulties that affect their health outcomes. Due to less understanding about medical conditions and treatment, worse health status and increased hospitalization rates are reported in such patients. Awareness of health literacy issue might be improved by creating awareness in medical students and physicians for effective patient-physician communication [7]. Therefore, the aim of the present review paper was to systematically analyze the concept of health literacy, its measurement tools and related barriers along with interventions used to improve health literacy in developed and developing countries including Pakistan.

\section{Methodology}

A systematic literature research was conducted for articles published from 1990 to 2016 using the electronic databases PubMed, EMBASE, Google Scholar, Psyc Info and Science direct. The search terms used with each database were literacy, health literacy and functional health literacy. Full text papers as well as abstracts were retrieved and included in review. A total of 54 studies were retrieved from databases related to health literacy. The studies were classified on the basis of their country of publishing into developed countries, developing countries and Pakistan. Thirty three studies from developed countries, 16 from developing countries and 5 studies from Pakistan were included in this review (Table 1). Quantitative cross sectional surveys as well longitudinal studies were included.

Table 1: Details of country and number of included papers.

\begin{tabular}{|c|c|c|}
\hline Regions & $\begin{array}{c}\text { Number of } \\
\text { studies }\end{array}$ & Countries \\
\hline $\begin{array}{c}\text { Developed } \\
\text { countries }\end{array}$ & 33 & $\begin{array}{c}\text { USA, UK, Canada, Brazil, } \\
\text { Poland, Ireland, Portugal }\end{array}$ \\
\hline $\begin{array}{c}\text { Developing } \\
\text { countries }\end{array}$ & 16 & $\begin{array}{c}\text { Turkey, South Africa, } \\
\text { Malaysia, India, Iran, } \\
\text { Nigeria, Philippines, } \\
\text { Turkey, Sudan, Yemen, } \\
\text { Angola, Mexico, Saudi } \\
\text { Arabia }\end{array}$ \\
\hline Pakistan & 5 & $\begin{array}{c}\text { - } \\
\text { Total }\end{array}$ \\
\hline
\end{tabular}

\section{Results and Discussion}

\section{Barriers to Health Literacy}

Poor health outcomes are associated with low health literacy due to inadequate clinician-patient, system-patient and community-patient communication [8]. Evidence supports that increased age, low education, low socioeconomic status and poor reading level are among the major barriers to health literacy [9]. Along with other socio-economic issues, literature reveals that one of the barriers faced by people having low health literacy level around the world is due to misunderstanding of health information in English language [10]. Ability to correctly read medical information declines with age [11]. Education is strongly linked with adequate health literacy. Poor understanding of health related information and ignorance leads to poor management of health among less educated population leading to early deaths [3]. A study conducted in eleven European Union countries concluded that secondary and tertiary education contributes in improving health related knowledge among individuals [12].

The more the level of education is attained, the more health knowledge is improved, personal empowerment is gained and self worth is valued [13]. Furthermore, evidence supports that cognitive impairment with age leads to difficulty in information processing and dementia and it is not linked with having less education among the elderly $[14,15]$. Low-income population majorly possesses low reading skills resulting in low health literacy [11]. Good level of earning contribute positively to managing health and taking proper self care [12]. Moreover, high prevalence of chronic diseases like hypertension, diabetes, hypercholesterolemia leading to cerebrovascular disease and stroke is among the major barriers to health literacy as all of these diseases affect mental abilities and disables brain to function properly [14]. People having both low literacy level and chronic diseases fail to manage their health problems as they lack basic understanding of managing their diseases [15].

\section{Tools for Assessment of Health Literacy}

Health literacy being a multi-dimensional concept comprises of an assemblage of skills. Thus, in order to develop a health literacy measuring tool, all the central pillars of health literacy need to be considered [16]. There are a limited number of tools available to measure functional health literacy among which the most widely used are the REALM, and the TOFHLA [1]. Moreover, most of the other available tools are derived from these two existing functional health literacy tools [16]. The NAAL and Adult Literacy and Life Skills (ALL) are other healthrelated literacy assessment tools [1]. The Newest Vital Sign (NVS) is also a FHL screening tool that is considered to be more adaptable in modern health care settings as it covers reading, numeracy skills and document literacy but when compared with the TOFHLA, there is a potential risk of overestimation of results [10]. In primary health care settings, the NVS is suitable for quick screening of patients' health literacy [17]. Reading ability is one of the important elements of health literacy for assessing health information and managing one's health according to it. For identifying limited reading ability among patients, the Single Item Literacy Screener (SILS) has been developed which helps the health care providers to offer additional counselling to such patients [18].

The European Health Literacy Survey Questionnaire (HLSEU-Q) developed by researchers is a novel and wide-ranging tool to measure health literacy in Europe but it requires to be 
validated in different countries for understanding of health literacy in other nations [19]. Swiss Health Literacy Survey has also been developed to broadly measure basic health related reading skills in alignment with the various definitions and conceptual models of health literacy. Its widespread use may provide further understanding of health literacy [10].

Researchers suggest that the health literacy measuring instruments are based on different concepts due to which they measure health literacy differently. Thus, the instrument should be selected according to mode of administration, intended purpose, available time and allocated resources [9]. Thus it is recommended that health literacy measure be selected according to the skills that individuals require in a specific context for example those diagnosed with cancer should know how to read and understand information about the diagnosis, how to analyze treatment options and how to interact with their health care provider [20]. It is better for therapist to use those screening tools that are time-efficient in order to quickly assess the patient's health literacy needs [21].

\section{Overview of Current Situation of Health Literacy in Developed Countries}

A study conducted in Europe reported that at least 1 in 10 Europeans have inadequate health literacy level [22]. Furthermore, in the US, one third of the English-speaking patients treated at public healthcare facilities possessed inadequate functional health literacy [15]. Approximately 90 million adults in the US reported by The Institute of Medicine face problems in comprehending and following health information [23]. Moreover, 75 million adults in the US are estimated to possess basic and less than basic health literacy [13]. Language barrier is also a problem of 4 million adults in the US and only $12 \%$ of the total adult populations are able to manage their health properly [2]. A US study concluded that people with inadequate health literacy have higher hospitalization rates and most of them fall in the age range of 70 to 79 years. The same study also reported association of low health literacy level with high mortality [13]. Comparative analysis of literature suggested that health literacy in Japanese is lower than that of Europeans [24]. In Ireland, 1 in 7 Irish adults have limited health literacy [25]. A study from San Francisco reported that primary care physicians rarely assessed the understanding level of patients with diabetes mellitus having low functional health literacy. Moreover, it was concluded that interactive communication between physician and diabetic patients can help to achieve good glycemic control [26]. Study conducted in the US revealed that low level of reading ability among women also limits family planning education. Thus, healthcare providers need to ensure clear understanding of medical information among women [11].

Another study from the US demonstrated that approximately half of the paediatricians had knowledge about communication errors related to patient care and also knew how to avoid them. However, they underutilized those techniques because of having limited time. Moreover, very few paediatricians were able to identify a parent with a literacy problem [27]. In the Australian population, $6.8 \%$ people have inadequate or marginal health literacy, $10.6 \%$ people have reading levels below the ninth grade while $26.0 \%$ people are at risk of having limited health literacy as identified by TOFHLA, REALM and NVS tool respectively [1]. Recent researches have provided evidence that low levels of health literacy are prevalent among the general community in Western countries and associated with negative health outcomes [28].

\section{Interventions used for Improving Health Literacy in Developed Countries}

Low health literacy is known to be a 'silent killer'. This can be tackled by closing the gaps between health messages and health messengers by using simplified language and including cultural appropriateness [5]. Literature review confirms that both written and verbal health information combined are necessary to improve the knowledge and level of satisfaction of care givers at the time of discharging their patients as compared to provision of verbal information only [5,6]. A study from the US developed a pictographic medication adherence self-efficacy scale for assessing medication adherence self-efficacy in those populations having lower literacy as well as other language challenges. This scale proved helpful in managing patients with chronic as well as long-term medical conditions such as diabetes and asthma [29]. Researchers from the US also adapted the Honoring the Gift of Heart Health (HGHH) curriculum developed by the National Heart, Lung, and Blood Institute to provide HGHH-based education to people with different levels of health literacy and reported significant improvement in heart attack knowledge and marginal improvement in stroke and general CVD knowledge [30].

Another study conducted in Maryland found that hospitalized HF patients receiving one hour face to face education prior to discharge were more compliant to self care behaviors at 30 days and had lower re-hospitalization and mortality rates at 180 days compared to those who only received standard written discharge information [31]. Health information is more easily conveyed through radio, television, audiotapes, compact discs, and videotapes rather than from written sources. Thus, healthcare providers may utilize such formats in order to ease the patient in understanding health information. As per the NAAL data, approximately $78 \%$ of older adults receive health-related information from health care professionals, $68 \%$ from radio and TV, and only $15 \%$ get information from the Internet [21]. A study from US suggested that telephone based osteoarthritis (OA) self-management support intervention could be beneficial for patients with $\mathrm{OA}$ who are racial/ethnic minorities and have low health literacy [32]. Furthermore, a study conducted in US utilized interactive videodisc technology and evaluated its impact on patients' therapy decision. Findings concluded that majority patients were able to take their own medical therapy 
decision after watching the short video program as it was easy to understand [33].

\section{Overview of Current Situation of Health Literacy in Developing Countries}

A study from Sao Paulo, Brazil concluded that 31.7\% people were found to have limited functional health literacy [34]. A cross-sectional survey of adults conducted in Isfahan revealed that approximately $79.6 \%$ of adults had inadequate health literacy. Majority of the people had fewer years of school education, had low financial status, and were females [35]. Another cross-sectional study from Belgrade provided evidence that limited functional health literacy is prevalent among primary health-care patients and its level differed by social and economic factors [36]. In a national survey of Taiwanese adults, almost 30\% were found to have low health literacy. Moreover, low health literacy was associated with poor mental health in Taiwan [37]. By assessing the knowledge and attitude of high school students regarding AIDS in Iran, it was seen that there were many misconceptions about its route of transmission [38].

In a qualitative study conducted in a peri-urban community near Kathmandu, Nepal, people were found to have inadequate knowledge about primary open-angle glaucoma (POAG) which was one of the reasons of late presentation to the hospital [39]. Literature from developing countries states that people with good level of health literacy are good in managing their health conditions. Diabetes patients with adequate and marginal health literacy are observed to have good glycemic control [40]. Satisfactory knowledge about medications among patients is necessary for proper adherence to their therapy. A crosssectional study among Palestinian geriatrics living with chronic disease concluded that the more the patients are knowledgeable, the more they will show adherence to their medications which will favorably lead to improved health outcomes and decline in health care costs [41]. A cross-sectional survey conducted in Isfahan concluded that low health literacy is more common in older adults [35]. Moreover, similar findings were observed in Taiwan [37].

\section{Interventions used for Improving Health Literacy in Developing Countries}

Providing written health related information to patients has proved to be very effective in educating and empowering them. Simple and brief patient information leaflets (PIL) having pictograms and text have increased the medicine related knowledge in South African patients as compared to a longer and complex text-only PIL [42]. After analyzing the health literacy level in China, it was inferred that periodic training of health educators is essential for improving health knowledge of general public thus having an impact on overall public health [43]. Paediatricians and other adolescent health professionals should show efforts in providing rational health information especially in resource-limited areas where access to primary health care and medications is limited [44].
As the burden of cardiovascular diseases is growing in the Mesoamerican region, patients need to be empowered for their disease self-management but due to various barriers including lack of access to information about disease, its symptoms, prevention and control as well as lack of straight communication between healthcare providers and patients, disease self-management is not possible. Appropriate guidance from providers and clear communication can support people for disease self-management [45]. A research which examined the sources from where adolescents seek health information in Mbarara Uganda reported that more than one in three used the internet to search for health information [44]. In a survey conducted in Iran, high school students acknowledged television as their most important source of information regarding AIDS [38]. A study conducted in Israel tested a model of Media Health Literacy (MHL) and analyzed its role in promoting empowerment and health behavior in different health aspects like smoking , balance dieting, role of exercise, personal safety, first aid knowledge and sexual behavior and it was concluded that MHL may provide a base for health promotion among youngsters [46].

\section{Overview of Current Situation of Health Literacy in Pakistan}

Pakistan's spending on education is the lowest in South Asia. The country is spending 0.5 to 0.8 per cent of its GDP on health for the last 10 years while WHO benchmark of health expenditure is at least 6 per cent of the GDP [47]. On the other hand, Pakistan has a literacy rate of $58 \%$ while according to the target given by the Millennium Development Goals (MDG), $88 \%$ literacy rate had to be achieved by the end of 2015 . Thus Pakistan is way behind the target of MDG [48]. UNESCO report indicates that over 70 percent of the world's adult illiterates live in only nine countries, out of which six are predominantly Muslim countries including Pakistan [49].

Evidence shows that majority of the Pakistani population has no access to basic health related information. A study reported that the general awareness level of public regarding stroke was inadequate and that $56 \%$ of the sampled population attained the basic information about stroke from their friends or relatives [50]. Misunderstanding drug labels and prescriptions is another issue faced by Pakistani population that undoubtedly leads to adverse drug events. A cross sectional study conducted in Karachi, reported that majority of the people fail to understand various medical terminologies related to dosage present on their prescriptions, those understanding English language were able to understand their prescribed regimen but still their understanding was not upto the mark which shows language as a barrier to rational use of medicines [51].

As the population is increasing day by day in Pakistan, healthcare providers are not present in number sufficient to provide their quality services to the nation. As estimated in the current scenario, the ratio 0.473 of physicians to 1,000 
population is more than inadequate to maintain the nation's health which is leading to adverse health conditions and increased economic burden [52]. Patients' information leaflet (PIL) being the primary source of information about the medication for patients' needs to be appropriately designed in order to educate them. A study evaluated the leaf inserts sold with marketed medicines in Pakistan and revealed the presence of incomplete medicine related information in PILs and complex to be understood by patients. Moreover, majority of PILs did not meet the regulatory requirements [53]. Caregivers should play a pivotal role in making their patients understand their prescriptions and drug labels in order to avoid adverse drug events [51]. Moreover, the involvement of media, doctors and religious scholars in educating people is an effective measure to enhance health knowledge [54].

\section{Conclusion}

The review paper concludes that the multiple dimensions of health literacy are still yet to be clearly explained. Most of the studies used either REALM or TOFHLA for measurement of health literacy, which are not sufficient for measuring health literacy beyond the ability to read and understand medical information. Furthermore, none of the available tools capture the complex aspects of health system navigation, such as health beliefs, negotiation skills, self-efficacy skills and illness management.

Although, health literacy in most of the developed countries is adequate but it is still questionable in developing countries including Pakistan. Most of the health literacy data is derived from the developed countries health care settings which make the transferability of data to developing countries ambiguous. Limited studies have examined impact of different interventions for improving health literacy especially in specific populations. Extensive research is required to explore economic implications of limited health literacy on the health system and the cost-effectiveness of interventions to improve health literacy. Furthermore, effectiveness of media literacy education addressing health and language barrier to comprehend medical instructions, prescriptions and drug labels should be investigated.

\section{References}

1. Barber MN, Staples M, Osborne RH, Clerehan R, Elder C, et al. (2009) Up to a quarter of the Australian population may have suboptimal health literacy depending upon the measurement tool: results from a population-based survey. Health Promotion International 24(3): 252 261.

2. Evangelista LS, Rasmusson KD, Laramee AS, Barr J, Ammon SE, et al. (2010) Health literacy and the patient with heart failure-implications for patient care and research: a consensus statement of the Heart Failure Society of America. Journal of cardiac failure 16(1): 9-16

3. Zarcadoolas C, A Pleasant, DS Greer(2005) Understanding health literacy: an expanded model. Health Promotion International 20(2): 195-203.

4. Berkman ND, TC Davis, L Mc Cormack (2010) Health literacy: what is it? Journal of health communication 15(S2): 9-19.
5. Zarcadoolas C (2011) The simplicity complex: exploring simplified health messages in a complex world. Health Promotion International 26(3): 338-350.

6. Johnson A, J Sandford (2005) Written and verbal information versus verbal information only for patients being discharged from acute hospital settings to home: systematic review. Health Education Research 20(4): 423-429.

7. Williams MV Davis T, Parker RM, Weiss BD (2002) The role of health literacy in patient-physician communication. Family medicine-kansas city $34(5): 383-389$.

8. Sudore RL D Schillinger (2009) Interventions to improve care for patients with limited health literacy. Journal of clinical outcomes management: JCOM 16(1): 20-29.

9. Haun J, Luther S, Dodd V, Donaldson P (2012) Measurement variation across health literacy assessments: implications for assessment selection in research and practice. Journal of health communication 17(sup3): 141-159.

10. Adams RJ, Appleton SL, Hill CL, Dodd M, Findlay C, et al. (2009) Risks associated with low functional health literacy in an Australian population. Med J Aust 191(10): 530-534.

11. Gazmararian JA, RM Parker, DW Baker (1999) Reading skills and family planning knowledge and practices in a low-income managed-care population. Obstetrics \& Gynecology 93(2): 239-244.

12. Albert C, MA Davia (2011) Education is a key determinant of health in Europe: a comparative analysis of 11 countries. Health Promotion International 26(2): 163-170.

13. Baker DW, Wolf MS, Feinglass J, Thompson JA, Gazmararian JA, et al. (2007) Health literacy and mortality among elderly persons. Archives of internal medicine 167(14): 1503-1509.

14. Baker DW, Gazmararian JA, Sudano J, Patterson (2000) The association between age and health literacy among elderly persons. The Journals of Gerontology Series B: Psychological Sciences and Social Sciences 55(6): S368-S374.

15. Baker DW, Gazmararian JA, Williams MV, Scott T, Parker RM, et al. (2002) Functional health literacy and the risk of hospital admission among Medicare managed care enrollees. American Journal of Public Health 92(8): 1278-1283.

16. Altin SV, Isabelle Finke, Sibylle Kautz-Freimuth, Stephanie Stock (2014) The evolution of health literacy assessment tools: a systematic review. BMC Public Health 14(1): 1207.

17. Weiss BD, Mays MZ, Martz W, Castro KM, DeWalt DA, et al. (2005) Quick assessment of literacy in primary care: the newest vital sign. The Annals of Family Medicine 3(6): 514-522.

18. Morris NS, Charles D MacLean, Lisa D Chew, Benjamin Littenberg (2006) The Single Item Literacy Screener: evaluation of a brief instrument to identify limited reading ability. BMC Family Practice $7(1): 21$.

19. Sørense k, Van den Broucke S, Pelikan JM, Fullam J, Doyle G, et al. (2013) Measuring health literacy in populations: illuminating the design and development process of the European Health Literacy Survey Questionnaire (HLS-EU-Q). BMC Public Health 13(1): 948.

20. Fransen MP, Rowlands G, Leenaars KE, Essink-Bot ML, et al. (2014) Self-rated literacy level does not explain educational differences in health and disease. Archiv Public Health 72(1): 14.

21. Ennis K, K Hawthorne, D Frownfelter (2012) How physical therapists can strategically effect health outcomes for older adults with limited health literacy. Journal of Geriatric Physical Therapy 35(3): 148-154.

22. Sørensen k, Pelikan JM, Röthlin F, Ganahl K, Slonska Z, et al. (2015) Health literacy in Europe: comparative results of the European health 
literacy survey (HLS-EU). The European Journal of Public Health 25(6): 1053-1058.

23. Davis TC, Wolf MS, Bass PF 3rd, Thompson JA, Tilson HH, et al. (2006) Literacy and misunderstanding prescription drug labels. Annals of Internal Medicine 145(12): 887-894.

24. Nakayama K, Wakako Osaka, Taisuke Togari, Hirono Ishikawa, Yuki Yonekura, et al. (2015) Comprehensive health literacy in Japan is lower than in Europe: a validated Japanese-language assessment of health literacy. BMC Public Health 15(1): 501.

25. Sahm LJ, Wolf MS, Curtis LM, McCarthy S (2012) Prevalence of limited health literacy among Irish adults. Journal of health communication 17(sup3): 100-108.

26. Schillinger D, Piette J, Grumbach K, Wang F, Wilson C, et al. (2003) Closing the loop: physician communication with diabetic patients who have low health literacy. Archives of internal medicine 163(1): 83-90.

27. Turner T, Cull WL, Bayldon B, Klass P, Sanders LM, et al. (2009) Pediatricians and health literacy: descriptive results from a national survey. Pediatrics 124(Supplement 3): S299-S305.

28. Begoray DL, B Kwan (2012) A Canadian exploratory study to define a measure of health literacy. Health Promotion International 27(1): 2332.

29. Kalichman SC, Cain D, Fuhrel A, Eaton L, Di Fonzo K, et al. (2005) Assessing medication adherence self-efficacy among low-literacy patients: development of a pictographic visual analogue scale. Health Education Research 20(1): 24-35.

30. Brega AG, Pratte KA, Jiang L, Mitchell CM, Stotz SA, et al. (2013) Impact of targeted health promotion on cardiovascular knowledge among American Indians and Alaska Natives. Health Education Research 28(3): 437-449.

31. Dennison CR, McEntee ML, Samuel L, Johnson BJ, Rotman S, et al. (2011) Adequate health literacy is associated with higher heart failure knowledge and self care confidence in hospitalized patients. The Journal of cardiovascular nursing 26(5): 359-367.

32. Sperber NR, Bosworth HB, Coffman CJ, Lindquist JH, Oddone EZ, et al. (2013) Differences in osteoarthritis self-management support intervention outcomes according to race and health literacy. Health Education Research 28(3): 502-511.

33. Spunt BS, Deyo RA, Taylor VM, Leek KM, Goldberg HI, et al. (1996) An interactive videodisc program for low back pain patients. Health Education Research 11(4): 535-541.

34. Apolinario D, Mansur LL, Carthery-Goulart MT, Brucki SM, Nitrini R, et al. (2014) Detecting limited health literacy in Brazil: development of a multidimensional screening tool. Health Promotion International 29(1): 5-14.

35. Javadzade SH, Sharifirad G, Radjati F, Mostafavi F, Reisi M, et al. (2012) Relationship between health literacy, health status, and healthy behaviors among older adults in Isfahan, Iran. Journal of Education and Health Promotion 1: 31

36. Jovic-Vranes A, V Bjegovic-Mikanovic, J Marinkovic (2009) Functional health literacy among primary health-care patients: data from the Belgrade pilot study. Journal of Public Health 31(4): 490-495.

37. Shoou-Yih D Lee, Tzu-I Tsai, Yi-Wen Tsai, Ken N Kuo (2010) Health literacy, health status, and healthcare utilization of Taiwanese adults: results from a national survey. BMC Public Health 10(1): 614.
38. Tavoosi A, Azadeh Zaferani,Anahita Enzevaei, Parvin Tajik, Zahra Ahmadinezhad, et al. (2004)Knowledge and attitude towards HIV/ AIDS among Iranian students. BMC Public Health 4(1): 17.

39. Shakya Vaidya S, Povlsen L, Shrestha B, Grjibovski AM, Krettek, et al. (2014) Understanding and living with glaucoma and noncommunicable diseases like hypertension and diabetes in the Jhaukhel0Duwakot Health Demographic Surveillance Site: a qualitative study from Nepal. Global health action : 7.

40. Chen GD, Huang CN, Yang YS, Lew-Ting CY, et al. (2014) Patient perception of understanding health education and instructions has moderating effect on glycemic control. BMC Public Health 14(1): 683.

41. Najjar A, Yazan Amro, Islam Kitaneh, Salam Abu-Sharar, Maryam Sawalha, et al. (2015) Knowledge and Adherence to Medications among Palestinian Geriatrics Living with Chronic Diseases in the West Bank and East Jerusalem. PloS one 10(6): e0129240.

42. Mansoor L, R Dowse (2007) Written medicines information for South African HIV/AIDS patients: does it enhance understanding of cotrimoxazole therapy? Health Education Research 22(1): 37-48.

43. Wang R (2000) Critical health literacy: a case study from China in schistosomiasis control. Health Promotion International 15(3): 269274.

44. Ybarra ML, Emenyonu N, Nansera D, Kiwanuka J, Bangsberg DR, et al. (2008) Health information seeking among Mbararan adolescents: results from the Uganda Media and You survey. Health Education Research 23(2): 249-258.

45. Fort MP, Alvarado-Molina N, Peña L, Mendoza Montano C, Murrillo S, et al. (2013) Barriers and facilitating factors for disease self-management: a qualitative analysis of perceptions of patients receiving care for type 2 diabetes and/or hypertension in San José, Costa Rica and Tuxtla Gutiérrez, Mexico. BMC Family Practice 14(1): 131.

46. Levin-Zamir D, D Lemish, R Gofin (2011) Media Health Literacy (MHL): development and measurement of the concept among adolescents. Health Education Research 26(2): 323-335.

47. (2017) Nation T, Pakistan Health.

48. (2016) Dawn. Pakistan Education.

49. Aftab T (1994) Fighting illiteracy: What works and what doesn't: A case study of female literacy in Pakistan. Convergence 27(4): 25-34.

50. Aly Z, Abbas K, Kazim SF, Taj F, Aziz F, et al. (2009) Awareness of stroke risk factors, signs and treatment in a Pakistani population. Journal of the Pakistan Medical Association 59(7): 495.

51. Patel MJ, Muhammad Shoaib Khan, Farheen Ali, Zehra Kazmi, Talha Riaz, et al. (2013) Patients' Insight of Interpreting Prescriptions and Drug Labels-A Cross Sectional Study. PloS one 8(6): e65019.

52. Talati JJ, G Pappas (2006) Migration, medical education, and health care: a view from Pakistan. Academic Medicine 81(12): S55-S62.

53. Arsalan A, Sameer Qureshi, Mehtab Alam, Sadia Ahmed, Osama Shakeel, et al. (2015) Errors in Patients' Information Leaflets of Marketed Medicines in Pakistan. Journal of Applied Pharmaceutical Science 5(05): 068-074.

54. Saleem T, Ishaque S, Habib N, Hussain SS, Jawed A, et al. (2009) Knowledge, attitudes and practices survey on organ donation among a selected adult population of Pakistan. BMC medical ethics 10(1): 5. 
This work is licensed under Creative Commons Attribution 4.0 License

DOI:_10.19080/JPCR.2017.04.555632

\section{Your next submission with Juniper Publishers} will reach you the below assets

- Quality Editorial service

- Swift Peer Review

- Reprints availability

- E-prints Service

- Manuscript Podcast for convenient understanding

- Global attainment for your research

- Manuscript accessibility in different formats ( Pdf, E-pub, Full Text, Audio)

- Unceasing customer service

Track the below URL for one-step submission https://juniperpublishers.com/online-submission.php 